\title{
Article \\ Identification of Pelvic Congestion Syndrome Using Transvaginal Ultrasonography. A Useful Tool
}

\author{
Irene Valero $^{1} \mathbb{D}^{\mathbb{D}}$, Rocio Garcia-Jimenez ${ }^{1} \mathbb{D}$, Pamela Valdevieso ${ }^{1}$, Jose A. Garcia-Mejido ${ }^{1,2}(\mathbb{D}$, \\ Jose V. Gonzalez-Herráez ${ }^{3}$, Irene Pelayo-Delgado ${ }^{4,5}$, Ana Fernandez-Palacin ${ }^{6, *}$ and Jose A. Sainz-Bueno ${ }^{1,2, * \mathbb{D}}$
}

1 Department of Obstetrics and Gynecology, Valme University Hospital, 3441014 Seville, Spain; irevalarr@gmail.com (I.V.); rociogarji@gmail.com (R.G.-J.); Joseantoniosainz@hotmail.es (P.V.); jagmejido@hotmail.com (J.A.G.-M.)

2 Department of Obstetrics and Gynecology, University of Seville, 3441014 Seville, Spain

3 Department of Angiology and Vascular Surgery, Valme University Hospital, 3441014 Seville, Spain; jvgonzalezherraez@hotmail.es

4 Department of Obstetrics and Gynecology, Ramón y Cajal University Hospital, 3428042 Madrid, Spain; ipelayod@yahoo.com

5 Department of Obstetrics and Gynecology, University of Alcalá de Henares, 3428803 Madrid, Spain

6 Biostatistics Unit, Department of Preventive Medicine and Public Health, University of Seville, 3428803 Seville, Spain

* Correspondence: afp@us.es (A.F.-P.); jsainz@us.es (J.A.S.-B.)

\section{check for}

Citation: Valero, I.; Garcia-Jimenez,

R.; Valdevieso, P.; Garcia-Mejido, J.A.; Gonzalez-Herráez, J.V.; Pelayo-

Delgado, I.; Fernandez-Palacin, A.; Sainz-Bueno, J.A. Identification of Pelvic Congestion Syndrome Using Transvaginal Ultrasonography. A Useful Tool. Tomography 2022, 8, 89-99. https://doi.org/10.3390/ tomography 8010008

Academic Editor: Emilio Quaia

Received: 18 October 2021

Accepted: 27 December 2021

Published: 4 January 2022

Publisher's Note: MDPI stays neutral with regard to jurisdictional claims in published maps and institutional affiliations.

Copyright: (C) 2022 by the authors. Licensee MDPI, Basel, Switzerland. This article is an open access article distributed under the terms and conditions of the Creative Commons Attribution (CC BY) license (https:// creativecommons.org/licenses/by/ $4.0 /)$.

\begin{abstract}
The gold standard for the diagnosis of pelvic congestion syndrome (PCS) is venography (VG), although transvaginal ultrasound (TVU) might be a noninvasive, nonionizing alternative. Our aim is to determine whether TVU is an accurate and comparable diagnostic tool for PCS. An observational prospective study including 67 patients was carried out. A TVU was performed on patients, measuring pelvic venous vessels parameters. Subsequentially, a VG was performed, and results were compared for the test calibration of TVU. Out of the 67 patients included, only 51 completed the study and were distributed in two groups according to VG results: 39 patients belonging to the PCS group and 12 to the normal group. PCS patients had a larger venous plexus diameter (15.1 mm vs. $12 \mathrm{~mm} ; p=0.009)$ and higher rates of crossing veins in the myometrium (74.35\% vs. $33.3 \% ; p=0.009)$, reverse or altered flow during Valsalva (58.9\% vs. $25 \% ; p=0.04)$, and largest pelvic vein $\geq 8 \mathrm{~mm}(92.3 \%$ vs. $25 \%)$. The sensitivity and specificity of TVU were $92.3 \%$ (95\% CI: 78.03-97.99\%) and 75\% (95\% CI: 42.84-93.31\%), respectively. In conclusion, transvaginal ultrasonography, with the described methodology, appears to be a promising tool for the diagnosis of PCS, with acceptable sensitivity and specificity.
\end{abstract}

Keywords: pelvic congestion syndrome; chronic pelvic pain; transvaginal ultrasound; venography

\section{Introduction}

Pelvic congestion syndrome (PCS) is one of the existing causes of chronic pelvic pain (CPP) in women, which consists of the dilation and stasis of the pelvic venous plexus. CPP is defined as the noncyclical pain in the hypogastric, lumbosacral, or perineal area, which lasts 6 months or longer. It is quite an important health problem that causes up to $40 \%$ of referrals for gynecology units [1,2].

Currently, the diagnosis of PCS remains a challenge, given that there are not universally accepted criteria for enlarged pelvic venous vessels. In recent years, the SymptomsVarices-Pathology (SVP) classification has been published for pelvic venous disorders, encompassing three domains: symptoms, varices, and pathophysiology, while also including the anatomy of abdominal and pelvic veins associated with hemodynamic anomalies and etiology. This instrument, once validated, could help to obtain homogeneous study groups with unified diagnostic criteria [3]. 
In addition, it is estimated that up to $15 \%$ of women between the ages of 20 and 50 years have varicose pelvic veins, although not all of them are symptomatic [4-6]. Most authors claim that the gold standard for the diagnosis of PCS is venography (VG) [2,7-9]. However, in recent years, some authors have proposed the use of computerized axial tomography (CT), magnetic resonance imaging (MRI), or transabdominal and transvaginal ultrasonography as alternatives $[7,10,11]$. CT and MRI imaging allow for an extensive view of the various causes of pelvic venous dilation, allowing us to use the SVP classification while also being able to detect additional findings such as the nutcracker syndrome or MayThurner syndrome, which have therapeutic implications [3,12]. A recent systematic review on the noninvasive diagnostic tools for PCS concluded that, although CT is accessible and fast technique, there are no studies available on its diagnostic value for PCS. Moreover, its ionizing properties are a disadvantage in terms of studying a population of mostly young women of fertile age. Regarding the MRI presents a high sensitivity raging between 88 and $100 \%$ while also allowing for the differential diagnosis with some other diseases such as endometriosis. However, the lack of standardized criteria regarding PCS, along with the small sample size in noncontrolled studies, and the limited availability in most clinics, makes it difficult for its recommendation [8].

In comparison with other techniques, transvaginal ultrasound (TVU) is an easily accessible, nonionizing, and minimally invasive technique. It allows for the measurement of pelvic veins and blood flow identification in real time [13]. The main disadvantage is that it requires the examiner to possess some experience, alongside the difficulty involved in properly identifying the ovarian veins. Several parameters have been proposed for the ultrasonographic diagnosis of PCS, such as the dilation of ovarian veins, low blood flow velocity in the ovarian vein, or a dilated arcuate vein in the myometrium communicating to pelvic varicosities [14]. Color Doppler imaging is essential to differentiate between cystic images from varicose veins. It also allows for the identification of reverse or abruptly interrupted flow during Valsalva, which is associated with the backflow or stasis of blood, respectively, identified in ovarian venography [4].

However, there still is some controversy regarding the reference values for the diameter of ovarian veins, with the pathological cut-off raging between 5 and $8 \mathrm{~mm}$. In this study, we aim to determine whether transvaginal 2D and Doppler ultrasonography are useful and reliable diagnostic tools for PCS in comparison with venography, as well as to establish ultrasound parameters for said purpose.

\section{Materials and Methods}

An observational and cross-sectional prospective study was carried out in the Gynecological Ultrasound Unit at the Valme University Hospital between November 2018 and July 2020. Patients were consecutively recruited, including all patients referred by the Pelvic Floor, Gynecology and Vascular Surgery Units, that met the inclusion criteria. The study was approved by Andalucia's board of biomedicine ethics committee (Code 1314/2017). All participants gave informed consent.

\subsection{Subjects}

The patients included in the study were distributed in two groups depending on whether the subsequent venography results confirmed the presence of PCS. The inclusion criteria were women presenting noncyclical pelvic pain for 6 months or longer. The exclusion criteria were the patient's refusal to undergo a venography.

\subsection{Data Collection}

For the collection of epidemiological data, the patients completed a questionnaire form prior to the diagnostic tests. These parameters were: age; parity; maximum newborn birth weight; menopausal stage; age of the onset of symptoms; worsening of symptoms after pregnancy; presence of vulvar varicosities during pregnancy; prior medical history of endometriosis, adenomyosis, urologic, or gastrointestinal disorders; presence of varicosities 
in lower extremities; prior pelvic surgery; presence of uterine fibroids; and the presence of varicosities in the vulva, perineum, buttocks, or lower extremities. In addition, patients stated the levels of pain they experienced in the following cases: walking, sitting, in the supine position, dysmenorrhea, dyspareunia, postcoital pain, and lumbar pain. Level of pain was considered clinically significant when the VAS score was 7 or higher.

\subsection{Ultrasound Assessment}

Ultrasonography assessment was performed by an expert examiner with more than 15 years of experience in gynecological ultrasonography, using a Canon Aplio 500 (Toshiba Medical systems Corp., Tokyo, Japan) with a $6.5 \mathrm{MHz}$ probe. Patients were placed in the gynecological position right after urinating in order to perform the assessment with an empty bladder, as is usual procedure for gynecological ultrasonography assessment.

The ultrasound evaluation began with the complete evaluation of the uterus in the longitudinal and cross-sectional planes, followed by the assessment of the adnexa. Uterine and ovarian volumes were calculated using the simplified formula for prolate ellipsoid [15]. Consecutively, we proceeded to identify the largest pelvic vein (after tracking the uterine vein from its origin at the internal cervical os to the internal iliac veins and collateral branches) along with the complete venous plexus, measuring their anteroposterior diameter in a cross-sectional plane. Subsequently, color and spectral Doppler was used to identify the flow direction and whether there was a change in the flow velocity waveform during Valsalva. The same procedure was repeated for the contralateral side. Afterwards, in a cross-sectional plane of the uterus, color Doppler was used to identify the presence of crossing veins in the myometrium, measuring its maximum anteroposterior diameter.

Therefore, the parameters collected in the ultrasound assessment were uterine volume, right and left ovarian volume, presence of polycystic ovaries (PCO), inner diameter of the largest pelvic vein (right and left side), maximum diameter of the largest venous plexus (right and left side), reverse or altered flow during Valsalva, presence of crossing veins in the myometrium, and maximum diameter of crossing veins in the myometrium. The ultrasonography diagnosis of PCS was based on the established cut-off point of $8 \mathrm{~mm}$ diameter for the largest pelvic venous vessel.

After the ultrasound assessment, patients underwent a pelvic venography, performed by specialists in angiology and vascular surgery. The diagnosis of PCS was based on the presence of the dilation of ovarian veins $\geq 10 \mathrm{~mm}$, congestion and/or valvular insufficiency $[16,17]$. If the diagnosis was confirmed, embolization was made during the same procedure in all 39 patients who were diagnosed with PCS.

\subsection{Statistical Analysis}

Statistical analysis was performed with the statistics software IBM SPSS version 22 (IBM, Armonk, NY, USA). Numeric variables were described as mean and standard deviations for normally distributed variables, while median and interquartile range were used for non-normally distributed variables. Percentages were used for qualitative variables. Normality of the data was made with the Shapiro-wilk test. Comparisons of numeric variables was evaluated using Student's $t$-test in case of normally distributed data, while the Mann-Whitney U-test was used for non-normally distributed data. The Chi-square test was used for comparisons of qualitative variables. Statistical significance was set at $p<0.05$.

\section{Results}

A total of 67 patients who met the inclusion criteria were invited to participate in the study. Out of the 67 patients included, only 51 completed the study and were distributed in two groups according to the venography results: 39 patients belonging to the PCS group (PCSG) and 12 to the normal group (NG).

There were no statistically significant differences between study groups regarding epidemiological data. The mean age of patients was $44.85 \pm 9.92$ and $41.5 \pm 6.95$ years in 
the PCSG and NG, respectively, with most women being multiparous (74.3\% PCSG; $91.6 \%$ NG). Only $11.8 \%$ of all patients were menopausal, as were $7.69 \%$ of the PCS patients. The mean age of the on-set of symptoms were 37 years in the PCSG and 31 years in the NG. Around $60 \%$ of PCS patients had vulvar varicosities during pregnancy, with worsening of the symptoms after pregnancy in $70 \%$ of them, which differs from the NG, in which only $50 \%$ of patients experienced said worsening of symptoms. The rest of the epidemiological variables showed similar results in both groups, with no statistically significant differences, as can be seen in Table 1 .

Table 1. Epidemiological data.

\begin{tabular}{|c|c|c|c|c|}
\hline Variables & PCS Group & Normal Group & All Patients & $p$ \\
\hline Age & $41.5 \pm 6.95$ & $44.85 \pm 9.92$ & $42.2 \pm 7.8$ & 0.212 \\
\hline Multiparity & $29(74.3 \%)$ & $11(91.6 \%)$ & $40(80 \%)$ & 0.197 \\
\hline Maximum newborn birth weight & $3565.56 \pm 546.7$ & $3665 \pm 442.14$ & $3591.9 \pm 518.5$ & 0.476 \\
\hline Menopausal & $3(7.69 \%)$ & $3(25 \%)$ & $6(11.8 \%)$ & 0.165 \\
\hline Age of the on-set of symptoms & $31.5 \pm 8.5$ & $37.25 \pm 12.7$ & $32.96 \pm 9.9$ & 0.847 \\
\hline Worsening of symptoms during pregnancy & $27(69.2 \%)$ & $5(41.6 \%)$ & $32(64 \%)$ & 0.119 \\
\hline Vulvar varicosities during pregnancy & $24(61.5 \%)$ & $8(66.6 \%)$ & $32(64 \%)$ & 0.83 \\
\hline $\begin{array}{c}\text { Medical history } \\
\text { Endometriosis } \\
\text { Adenomyosis } \\
\text { Urologic disorders } \\
\text { Gastrointestinal disorders } \\
\text { Varicosities in lower extremities }\end{array}$ & $\begin{array}{c}33(84.6 \%) \\
1(2.5 \%) \\
1(2.5 \%) \\
3(7.69 \%) \\
0(0 \%) \\
27(69.2 \%)\end{array}$ & $\begin{array}{c}10(83.3 \%) \\
1(8.3 \%) \\
2(16.6 \%) \\
0(0 \%) \\
1(8.3 \%) \\
6(50 \%)\end{array}$ & $\begin{array}{c}43(84.3 \%) \\
2(3.9 \%) \\
3(5.9 \%) \\
3(5.9 \%) \\
1(2 \%) \\
33(64.7 \%)\end{array}$ & $\begin{array}{l}0.396 \\
0.449 \\
0.156 \\
0.405 \\
0.255 \\
0.105\end{array}$ \\
\hline Prior pelvic surgery & $3(7.9 \%)$ & $2(16.6 \%)$ & $5(9.8 \%)$ & 0.378 \\
\hline Fibroids & $4(10.2 \%)$ & $3(25 \%)$ & $7(13.7 \%)$ & 0.256 \\
\hline $\begin{array}{c}\text { Presence of varicosities (vulva, perineum, } \\
\text { buttocks, lower extremities) }\end{array}$ & $29(74.3 \%)$ & $7(58.3 \%)$ & $36(70.6 \%)$ & 0.14 \\
\hline $\begin{array}{c}\text { Pain (VAS score } \geq 7 \text { ) } \\
\text { Walking } \\
\text { Sitting } \\
\text { Supine } \\
\text { Dysmenorrhea } \\
\text { Dyspareunia } \\
\text { Postcoital pain } \\
\text { Lumbar pain }\end{array}$ & $\begin{array}{l}21(53.8 \%) \\
19(48.7 \%) \\
15(28.4 \%) \\
23(58.9 \%) \\
16(41 \%) \\
22(56.5 \%) \\
13(33.3 \%)\end{array}$ & $\begin{array}{l}7(58.3 \%) \\
4(33.3 \%) \\
5(41.6 \%) \\
7(58.3 \%) \\
4(33.3 \%) \\
9(75 \%) \\
4(33.3 \%)\end{array}$ & $\begin{array}{l}28(56 \%) \\
23(46 \%) \\
20(40 \%) \\
30(60 \%) \\
20(40 \%) \\
31(62 \%) \\
17(34 \%)\end{array}$ & $\begin{array}{l}0.856 \\
0.2 \\
0.895 \\
0.599 \\
0.43 \\
0.532 \\
0.775\end{array}$ \\
\hline
\end{tabular}

PCS: Pelvic congestion syndrome; VAS: Visual Analogue Scale.

Regarding ultrasound variables, results are shown in Table 2. There were statistically significant differences in the presence of reverse or altered flow during Valsalva (58.9\% PCSG vs. 25\% NG; $p=0.04)$ and crossing veins in the myometrium $(74.35 \%$ PCSG vs. $33.3 \%$ NG; $p=0.009$ ). There were no differences between groups in the diameters of right or left venous plexus, although, when comparing the diameters of the largest venous plexus with both sides combined, we found that PCS patients had a larger venous plexus diameter than normal patients $(15.1 \mathrm{~mm}$ vs. $12 \mathrm{~mm} ; p=0.009)$. The presence of any pelvic vein of $\geq 8 \mathrm{~mm}$ was also significatively higher in PCS patients $(92.3 \%$ vs. $25 \% ; p<0.000)$. None of the rest of ultrasound variables reached statistical significance. 
Table 2. Ultrasound Parameters.

\begin{tabular}{|c|c|c|c|c|}
\hline Variables & PCS Group & Normal Group & All Patients & $p$ \\
\hline Uterine volume & $80 \pm 30.8$ & $73 \pm 66.8$ & $79.7 \pm 41.4$ & 0.626 \\
\hline Right ovarian volume & $9.94 \pm 6.2$ & $13.6 \pm 13.1$ & $10.65 \pm 8$ & 0.514 \\
\hline Left ovarian volume & $12.64 \pm 8.5$ & $15.2 \pm 14.4$ & $13.26 \pm 9.9$ & 0.5 \\
\hline $\mathrm{PCO}$ & $6(15.8 \%)$ & $3(23.1 \%)$ & $9(17.6 \%)$ & 0.552 \\
\hline Largest pelvic vein $\varnothing$ & $6.3 \pm 4.5$ & $4.8 \pm 1.3$ & $5.9 \pm 2.8$ & 0.308 \\
\hline Right side & $6.8 \pm 12.4$ & $3.9 \pm 1.7$ & $5.9 \pm 10.5$ & 0.411 \\
\hline Left side & $6.1 \pm 3.2$ & $4.7 \pm 2.1$ & $5.7 \pm 2.9$ & 0.187 \\
\hline Largest venous plexus $\varnothing$ & $15.1 \pm 6.4$ & $12 \pm 5.2$ & $16.9 \pm 12.1$ & 0.009 \\
\hline Right side & $14.3 \pm 7.9$ & $10.5 \pm 5.3$ & $13.4 \pm 7.4$ & 0.185 \\
\hline Left side & $18.4 \pm 13.1$ & $9.5 \pm 4.3$ & $15.9 \pm 12.03$ & 0.155 \\
\hline Reverse of altered flow during Valsalva & $23(58.9 \%)$ & $3(25 \%)$ & $26(51 \%)$ & 0.04 \\
\hline Crossing veins in the myometrium & $29(74.35 \%)$ & $4(33.3 \%)$ & $33(64.7 \%)$ & 0.009 \\
\hline Crossing veins in the myometrium $\varnothing$ & $3.5 \pm 1.99$ & $6 \pm 4.2$ & $3.75 \pm 2.25$ & 0.141 \\
\hline Pelvic vein $\varnothing \geq 8 \mathrm{~mm}$ & $36(92.3 \%)$ & $3(25 \%)$ & $39(76.5 \%)$ & $<0.000$ \\
\hline
\end{tabular}

PCS: Pelvic congestion syndrome; PCO: Polycystic ovaries; Ø: Diameter.

We also evaluated whether there were discrepancies in parameters based on laterality, given the anatomical differences for venous return. We found that the largest pelvic vein on the left side had a larger diameter than the one on the right side ( $6 \mathrm{~mm}$ vs. $4.5 \mathrm{~mm} ; p=0.011$ ). Ovarian volume and the venous plexus diameter did not reach statistical significance, as can be seen in Table 3 .

Table 3. Evaluation of differences based on laterality.

\begin{tabular}{cccc}
\hline Variables & Left Side & Right Side & $p$ \\
\hline Ovarian volume & $8 \pm 15.4$ & $7.4 \pm 7.99$ & 0.646 \\
\hline Largest pelvic vein $\varnothing$ & $6 \pm 3.6$ & $4.5 \pm 1.88$ & 0.011 \\
\hline Largest venous plexus $\varnothing$ & $15.2 \pm 8.75$ & $15.5 \pm 9.75$ & 0.359 \\
\hline Ø: Diameter
\end{tabular}

Ø: Diameter.

For the evaluation of the TVU diagnostic accuracy of PCS, in comparison with the diagnostic gold standard pelvic venography (Table 4), we established the TVU diagnostic criteria as the presence of any pelvic vein of $8 \mathrm{~mm}$ diameter or larger. In Table 5, we can see that TVU, using this cut-off point, had a sensitivity and specificity of $92.31 \%$ and $75 \%$, respectively, with false positive and false negative rates of $7.69 \%$ and $25 \%$. Positive and negative predictive values were $92.28 \%$ and $75.07 \%$, respectively, for a PCS prevalence of $76.4 \%$.

Table 4. Evaluation of the transvaginal ultrasound diagnostic accuracy of pelvic congestion syndrome using the criteria of any pelvic vein diameter of $8 \mathrm{~mm}$ or larger.

\begin{tabular}{cccccc}
\hline & & Venography (Gold Standard) & & Total & $p$ \\
\hline \multirow{2}{*}{$\begin{array}{c}\text { Transvaginal } \\
\text { Ultrasound }\end{array}$} & Normal & PCS & 3 & 12 & \\
\cline { 2 - 5 } & PCS & 9 & 36 & 39 & 51 \\
\hline
\end{tabular}

PCS: Pelvic congestion syndrome. 
Table 5. Diagnostic values of transvaginal ultrasound for pelvic congestion syndrome using the criteria of any pelvic vein diameter of $8 \mathrm{~mm}$ or larger.

\begin{tabular}{ccc}
\hline Transvaginal Ultrasound & Value & CI 95\% \\
\hline Sensitivity & $92.31 \%$ & $78.03-97.99 \%$ \\
\hline Specificity & $75 \%$ & $42.84-93.31 \%$ \\
\hline Positive predictive value & $92.28 \%$ & $81.71-96.97 \%$ \\
\hline Negative predictive value & $75.07 \%$ & $49.18-90.36 \%$ \\
\hline False positive rate & $7.69 \%$ & $2.01-21.97 \%$ \\
\hline False negative rate & $25 \%$ & $6.7-57.16 \%$ \\
\hline
\end{tabular}

In addition, a secondary analysis was performed to evaluate whether factors known to increase pelvic veins diameters (parity, premenopause, adenomyosis, fibroids, and PCO) were associated with larger pelvic veins or venous plexus diameters. No statistically significant differences were observed in this regard (Table 6).

Table 6. Assessment of factors associated with larger diameters of pelvic veins.

\begin{tabular}{cccc}
\hline Transvaginal Ultrasound & Nulliparous & Multiparous & $p$ \\
\hline Largest pelvic vein $\varnothing$ & $5.6 \pm 2.3$ & $6.2 \pm 2.9$ & 0.25 \\
\hline Largest venous plexus $\varnothing$ & $16 \pm 4.55$ & $17.2 \pm 12.6$ & 0.75 \\
\hline Largest pelvic vein $\varnothing$ & Premenopause & Menopause & $p$ \\
\hline Largest venous plexus $\varnothing$ & $6.2 \pm 2.8$ & $4.9 \pm 2.1$ & 0.43 \\
\hline & $16 \pm 7.3$ & $27.5 \pm 35.2$ & 0.33 \\
\hline Largest pelvic vein $\varnothing$ & No adenomyosis & Adenomyosis & $p$ \\
\hline Largest venous plexus $\varnothing$ & $5.8 \pm 2.8$ & $6.9 \pm 0.21$ & 0.33 \\
\hline & $15.9 \pm 11.6$ & - & - \\
\hline Largest pelvic vein $\varnothing$ & No fibroids & Fibroids & $p$ \\
\hline Largest venous plexus $\varnothing$ & $6.1 \pm 2.9$ & $6.2 \pm 0.61$ & 0.7 \\
\hline & $17.1 \pm 12.4$ & $16.5 \pm 5.7$ & 0.17 \\
\hline Largest pelvic vein $\varnothing$ & Normal ovaries & PCO & $p$ \\
\hline Largest venous plexus $\varnothing$ & $6.11 \pm 2.9$ & $6.2 \pm 1.8$ & 0.44 \\
\hline : Diameter. & $17.7 \pm 12.8$ & $14 \pm 4.8$ & 0.98 \\
\hline
\end{tabular}

\section{Discussion}

It is difficult to know the real incidence of PCS given the lack of definitive diagnostic criteria. It is estimated that the prevalence of PCS, although underdiagnosed, ranges between 16 and $30 \%$ of CPP patients in whom other causes have been discarded [18]. In our study, PCS prevalence was $76.4 \%$. This discrepancy might be explained by the fact that our patients were referred after a directed anamnesis and examination by a specialist in angiology and vascular surgery, which might have caused some selection bias.

This disorder is usually diagnosed in multiparous women aged between 30 and 40 years, who suffer a worsening of symptoms after pregnancy, usually with the onset of vulvar varicosities during said period. The explanation might lie in the increase of up to $50 \%$ of the pelvic venous vessels' capacity during pregnancy, which would lead to venous insufficiency and backflow after pregnancy $[2,4,18]$. In our study, the mean age of PCS patients was 41 years, while the on-set of symptoms was at 31 years. This 10-year delay could be based on the unawareness of this disorder by both patients and medical professionals. Pelvic venous insufficiency is frequent in multiparous women 
due to major strains on the venous system during pregnancy. Despite this, we did not find an association between PCS and multiparity, varicose veins during pregnancy, or a worsening of symptoms after pregnancy, although the latter was $20 \%$ more frequent in the PCS group [19].

Typically, PCS is considered a specific condition of premenopausal women, which is explained by the decrease in estrogen and its vasodilator effect in menopause. This explanation is backed by the improvement patients experience after pharmacological or surgical induction of a hypoestrogenic state [20]. Nonetheless, the etiology and physiology of PCS is multifactorial, thus we did not consider menopause as an exclusion criterion, with $7.69 \%$ of PCS patients being in menopausal stage.

The most frequent symptoms of PCS are dysmenorrhea (84\%), dyspareunia, and postcoital pain (40.8\%), which are usually accompanied by varicosities in the vulva (45.9\%) or in the lower extremities (58.7\%) [18]. Our results are similar to this data, except our dysmenorrhea rate in PCS patients was somewhat lower (58.9\%).

It is also worth mentioning that, in our study, we found that pelvic veins on the left side were significantly larger than on the right side, which is in agreement with the established higher prevalence of PCS on the left side, given the existing anatomical differences between both sides [21].

The main controverse in the diagnosis of PCS is the lack of consensus for what should be considered as enlarged pelvic venous vessels. It is worth mentioning that the existence of anatomical variations in the pelvic venous network may increase the difficulty of its standardization and, moreover, the collapse of the varicose veins due to the filling of the bladder when performing a transabdominal ultrasound assessment may increase difficulty in this regard. The mean ovarian vein diameter is $3.8 \mathrm{~mm}$ when valves are competent and $7.5 \mathrm{~mm}$ if they are incompetent, therefore the cut-off point for dilated pelvic veins was set at $5 \mathrm{~mm}$. Thus, the dilation is considered mild if the diameter is between 5 and $7.9 \mathrm{~mm}$ or severe if it is of $8 \mathrm{~mm}$ or larger. However, some authors have only used the cut-off point of $5 \mathrm{~mm}$, and even apply the same criterion for any pelvic vein. Given these discrepancies, a comparison of existing articles remains challenging [20,22]. Even more, whilst ovarian vein imaging is feasibly achievable by venography or tomography, their small size and variable location increase the difficulty of obtaining images by TVU.

Hence, the established criteria in our study for the ultrasonography diagnosis of PCS was the presence of any dilated pelvic vein, with the cut-off point for dilation being $8 \mathrm{~mm}$ (severe dilation), with the aim of establishing a reproducible technique.

To date, venography is still considered the gold standard for the diagnosis of PCS, despite being an invasive technique that can only be performed in specialized centers, which makes the introduction of new methods, such as ultrasonography, a necessity. A meta-analysis including six studies that compared TVU with venography described sensitivity and specificity rates ranging between 83 and $100 \%$ for the identification of pelvic varicocele or ovarian vein $\geq 5 \mathrm{~mm}$. However, it concluded that more studies are needed, given the flawed methodology and heterogeneity of parameters $[7,8,10,20,23]$.

Our main objective was to determine whether TVU is reliable for the diagnosis of PCS and if it is comparable to venography, as well as to establish ultrasound parameters for said purpose. Our results show that some ultrasound parameters are associated with the PCS, such as a reverse or altered flow during Valsalva, the presence crossing veins in the myometrium, and a larger maximum diameter of pelvic venous plexus. Even more, the ultrasound criteria for the PCS established in this studio (any pelvic vein of $\geq 8 \mathrm{~mm}$ diameter) showed good sensitivity (92.31\%) and acceptable specificity (75\%), with a low false positive rate $(7.69 \%)$. Even more, our study showed a high positive predictive value $(92.28 \%)$ when the PCS prevalence was of $76.4 \%$ or, in other words, with clinical suspicion of PCS. Therefore, TVU is a valid alternative for venography that could be used in the first assessment of patients suspected of having PCS. Images of these significant ultrasound variables are displayed in Figures 1-4 and Videos S1 and S2. Comparative venography images are shown in Figure 5. 


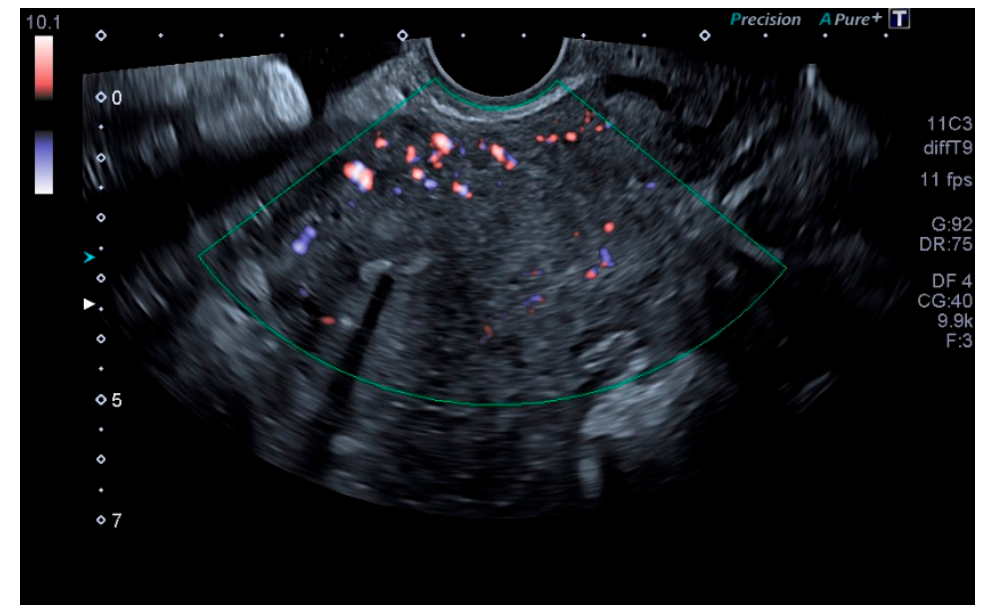

Figure 1. Crossing veins in the myometrium.

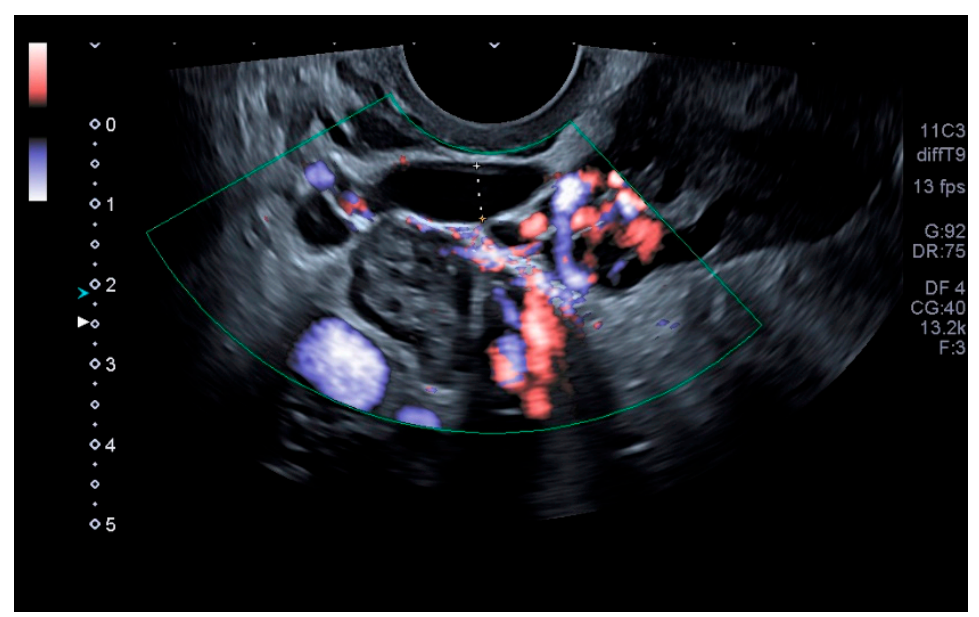

Figure 2. Largest pelvic vein diameter measurement.

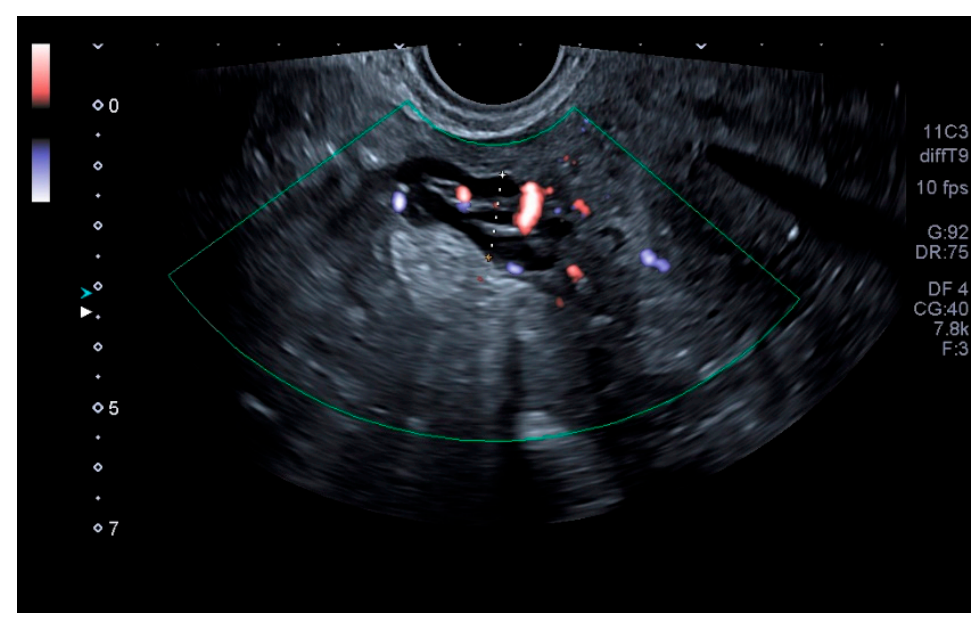

Figure 3. Largest venous plexus diameter measurement. 


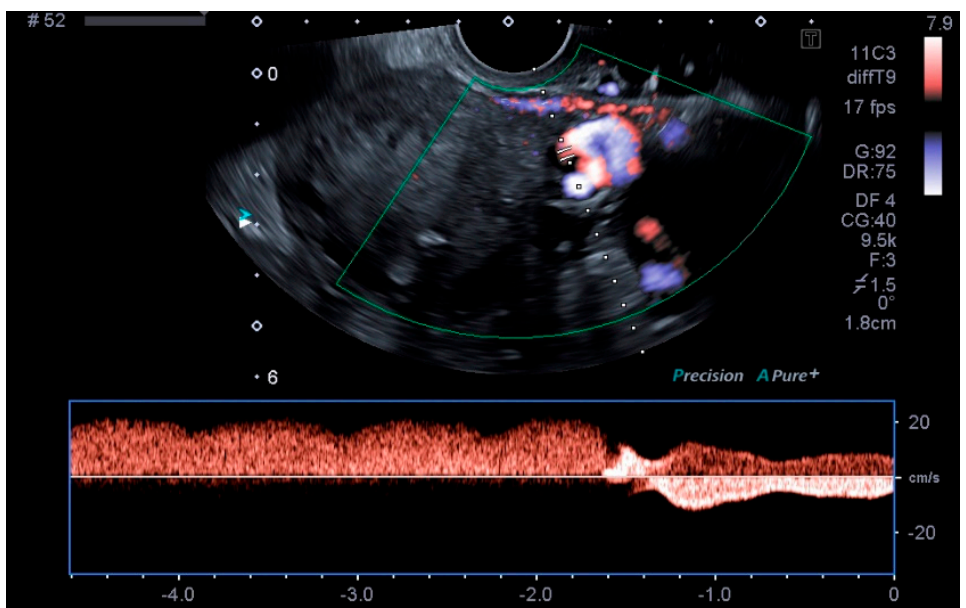

Figure 4. Reverse flow during Valsalva.

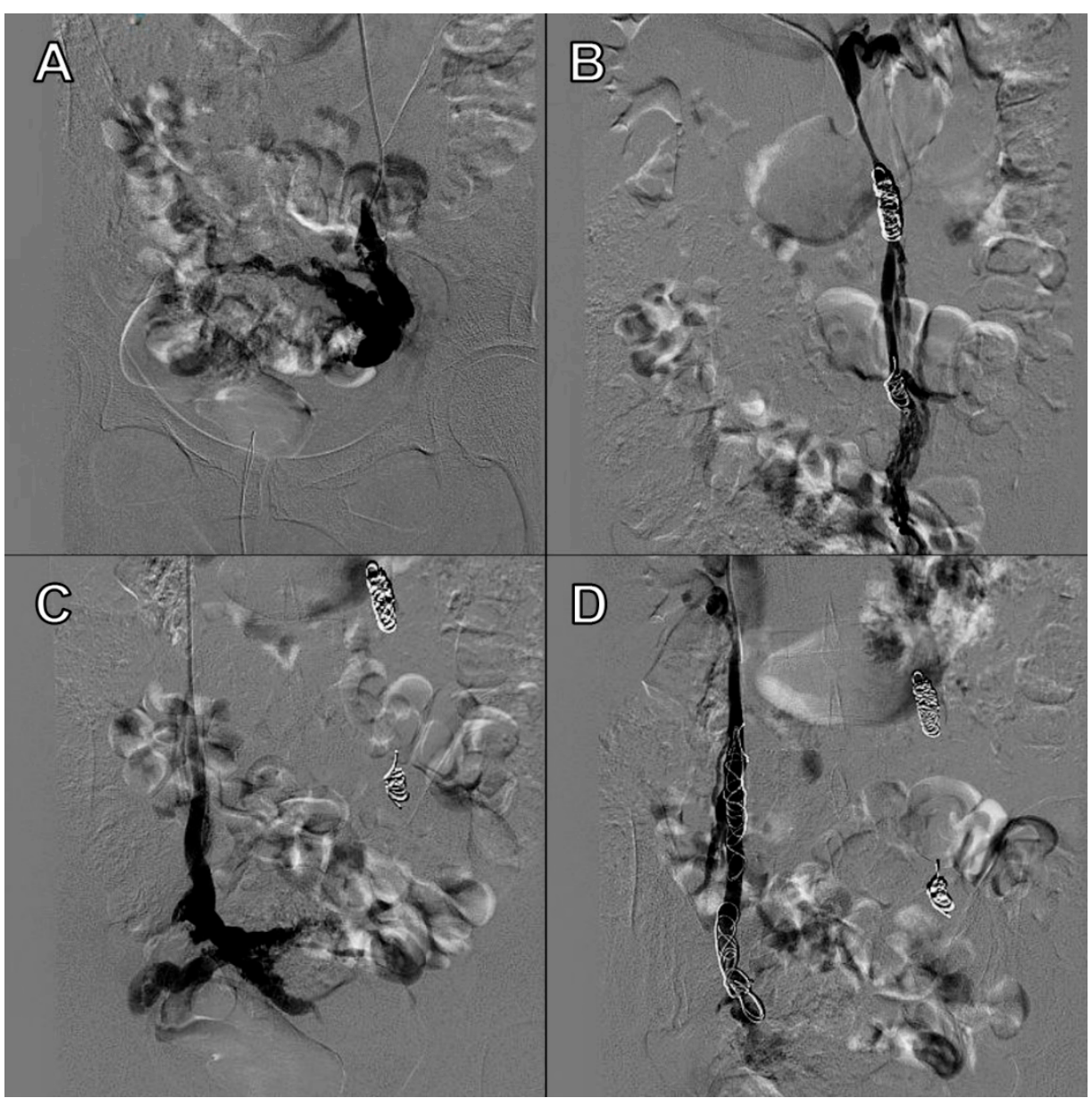

Figure 5. Venography sequence: (A) Insufficient left ovarian vein with periuterine varices. (B) Competent left ovarian vein after embolization. (C) Insufficient right ovarian vein with periuterine varices. (D) Competent right ovarian vein after embolization.

Previous studies have described that the presence of PCO and other factors known to increase uterine volume, such as parity, premenopause, adenomyosis, or fibroids, are associated with larger diameters of pelvic veins. Thus, patients with these characteristics would require different cut-off points [20,22]. In our study, these patients showed no increased venous diameters, hence no different cut-off points were made. 
Our study also has its limitations, one of them being the small sample size. It should also be mentioned that the ultrasound evaluation was performed by only one expert examiner in just a single act, and thus we were not able analyzed the intra- and interobserver reproducibility. We believe that our promising results should be confirmed in future studies, where they would be carried out by nonexpert examiners, and where the inter- and intra-observer reproducibility could be studied. It is also worth mentioning that patients were not required to remain seated or in supine position for a period of time, nor did they fast overnight before the ultrasound assessment, which might have hindered the correct visualization of venous structures due to the interference of intestinal gas. These limitations will be considered in future studies.

\section{Conclusions}

Transvaginal 2D and Doppler ultrasonography, with the described methodology, has acceptable sensitivity and specificity values. Our findings suggest that transvaginal ultrasonography seems to be a promising tool for the diagnosis of pelvic congestion syndrome.

Supplementary Materials: The following are available online at https:/ /www.mdpi.com/article/10 .3390/tomography8010008/s1, Video S1: Crossing veins in the myometrium, Video S2: Reverse flow during Valsalva.

Author Contributions: Conceptualization, J.A.S.-B. and J.V.G.-H.; methodology, A.F.-P.; formal analysis, A.F.-P.; data curation, P.V., J.A.G.-M.; writing-original draft preparation, I.V., R.G.-J., J.A.S.-B.; writing-review and editing, I.V., R.G.-J., J.A.S.-B.; J.A.G.-M., A.F.-P., J.V.G.-H., P.V., I.P.-D. All authors have read and agreed to the published version of the manuscript.

Funding: This research received no external funding.

Institutional Review Board Statement: The study was conducted according to the guidelines of the Declaration of Helsinki, and approved by Ethics Committee of VALME UNIVERSITARY HOSPITAL (protocol code 1314/2017) and date of approval (5-10-2017).

Informed Consent Statement: Informed consent was obtained from all subjects involved in the study.

Conflicts of Interest: The authors declare no conflict of interest.

\section{References}

1. Taylor, H.C. Vascular congestion and hyperemia. Am. J. Obstet. Gynecol. 1949, 57, 211-230. [CrossRef]

2. Beard, R.; Pearce, S.; Highman, J.; Reginald, P. Diagnosis of pelvic varicosities in women with chronic pelvic pain. Lancet 1984, 324, 946-949. [CrossRef]

3. Meissner, M.H.; Khilnani, N.M.; Labropoulos, N.; Gasparis, A.P.; Gibson, K.; Greiner, M.; Learman, L.A.; Atashroo, D.; Lurie, F.; Passman, M.A. The Symp-toms-Varices-Pathophysiology classification of pelvic venous disorders: A report of the American Vein \& Lymphatic Society International Working Group on Pelvic Venous Disorders. J. Vasc. Surg. Venous Lymphat. Disorder. 2021, 9, 568-584.

4. $\quad$ Park, S.J.; Lim, J.W.; Ko, Y.T.; Lee, D.H.; Yoon, Y.; Oh, J.H.; Lee, H.K.; Huh, C.Y. Diagnosis of Pelvic Congestion Syndrome Using Transabdominal and Transvaginal Sonography. Am. J. Roentgenol. 2004, 182, 683-688. [CrossRef]

5. Harris, R.D.; Holtzman, S.R.; Poppe, A.M. Clinical outcome in female patients with pelvic pain and normal pelvic US findings. Radiology 2000, 216, 440-443. [CrossRef] [PubMed]

6. Arnoldussen, C.W.K.P.; Wolf, M.A.F.D.; Wittens, C.H.A. Diagnostic imaging of pelvic congestive syndrome. Phlebol. J. Venous Dis. 2015, 30, 67-72. [CrossRef]

7. Ganeshan, A.; Upponi, S.; Hon, L.-Q.; Uthappa, M.C.; Warakaulle, D.R.; Uberoi, R. Chronic Pelvic Pain due to Pelvic Congestion Syndrome: The Role of Diagnostic and Interventional Radiology. Cardiovasc. Interv. Radiol. 2007, 30, 1105-1111. [CrossRef]

8. Steenbeek, M.P.; van der Vleuten, C.J.M.; Schultze Kool, L.J.; Nieboer, T.E. Noninvasive diagnostic tools for pelvic congestion syndrome: A systematic review. Acta Obstet. Gynecol. Scand. 2018, 97, 776-786. [CrossRef]

9. Gloviczki, P.; Comerota, A.J.; Dalsing, M.C.; Eklof, B.G.; Gillespie, D.; Gloviczki, M.L.; Lohr, J.M.; McLafferty, R.B.; Meissner, M.H.; Murad, M.H.; et al. The care of patients with varicose veins and associated chronic venous diseases: Clinical practice guidelines of the Society for Vascular Surgery and the American Venous Forum. J. Vasc. Surg. 2011, 53, 2S-48S. [CrossRef]

10. Malgor, R.D.; Adrahtas, D.; Spentzouris, G.; Gasparis, A.P.; Tassiopoulos, A.K.; Labropoulos, N. The role of duplex ultrasound in the workup of pelvic congestion syndrome. J. Vasc. Surg. Venous Lymphat. Disord. 2014, 2, 34-38. [CrossRef]

11. Freedman, J.; Ganeshan, A.; Crowe, P.M. Pelvic congestion syndrome: The role of interventional radiology in the treatment of chronic pelvic pain. Postgrad. Med. J. 2010, 86, 704-710. [CrossRef] 
12. Smith, M. Sonographic View of Pelvic Congestion Syndrome. J. Diagn. Med. Sonogr. 2017, 33, 193-198. [CrossRef]

13. Whiteley, M.S.; Dos Santos, S.; Harrison, C.C.; Holdstock, J.M.; Lopez, A.J. Transvaginal duplex ultrasonography appears to be the gold standard investigation for the haemodynamic evaluation of pelvic venous reflux in the ovarian and internal iliac veins in women. Phlebol. J. Venous Dis. 2014, 30, 706-713. [CrossRef] [PubMed]

14. Knuttinen, M.-G.; Xie, K.; Jani, A.; Palumbo, A.; Carrillo, T.; Mar, W. Pelvic Venous Insufficiency: Imaging Diagnosis, Treatment Approaches, and Therapeutic Issues. Am. J. Roentgenol. 2015, 204, 448-458. [CrossRef] [PubMed]

15. Swanson, M.; Sauerbrei, E.E.; Cooperberg, P.L. Medical implications of ultrasonically detected polycystic ovaries. J. Clin. Ultrasound 1981, 9, 219-222. [CrossRef] [PubMed]

16. Coakley, F.V.; Varghese, S.L.; Hricak, H. CT and MRI of Pelvic Varices in Women. J. Comput. Assist. Tomogr. 1999, $23,429-434$. [CrossRef]

17. Geier, B.; Barbera, L.; Mumme, A.; Köster, O.; Marpea, B.; Kaminsky, C.; Asciutto, G. Reflux patterns in the ovarian and hypogastric veins in patients with varicose veins and signs of pelvic venous incompetence. Chir. Ital. 2007, 59, 481-488.

18. Corrêa, M.P.; Bianchini, L.; Saleh, J.N.; Noel, R.S.; Bajerski, J.C. Síndrome da congestão pélvica e embolização de varizes pélvicas. J. Vasc. Bras. 2019, 18, 20190061. [CrossRef]

19. Leiber, L.; Thouveny, F.; Bouvier, A.; Labriffe, M.; Berthier, E.; Aube, C.; Willoteaux, S. MRI and venographic aspects of pelvic venous insufficiency. Diagn. Interv. Imaging 2014, 95, 1091-1102. [CrossRef]

20. Díaz- Reyes, C.G. Várices pélvicas y síndrome de congestión pélvica en la mujer. Rev. CES Med. 2012, 26, 57-69.

21. Ahlberg, N.E.; Bartley, O.; Chidekel, N. Right and left gonadal veins. An anatomical and statistical study: An anatomical and statistical study. Acta Radiol. Diagn. 1966, 4, 593-601. [CrossRef] [PubMed]

22. Amin, T.N.; Wong, M.; Foo, X.; Pointer, S.-L.; Goodhart, V.; Jurkovic, D. The effect of pelvic pathology on uterine vein diameters. Ultrasound J. 2021, 13, 7. [CrossRef] [PubMed]

23. Sharma, K.; Bora, M.K.; Varghese, J.; Malik, G.; Kuruvilla, R. Role of trans vaginal ultrasound and Doppler in diagnosis of pelvic congestion syndrome. J. Clin. Diagn. Res. 2014, 8, OD05-OD07. [CrossRef] [PubMed] 